BMJ Open

Diabetes

Research

\& Care

\section{Association between self-stigma and self-care behaviors in patients with type 2 diabetes: a cross-sectional study}

To cite: Kato A, Fujimaki Y, Fujimori S, et al. Association between self-stigma and selfcare behaviors in patients with type 2 diabetes: a crosssectional study. BMJ Open Diabetes Research and Care 2016:4:e000156. doi:10.1136/bmjdrc-2015000156

- Additional material is available. To view please visit the journal (http://dx.doi.org/ 10.1136/bmjdrc-2015000156)

Received 28 September 2015 Revised 24 November 2015 Accepted 9 December 2015

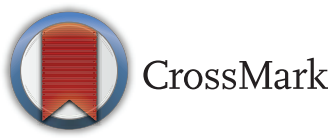

For numbered affiliations see end of article.

Correspondence to Dr Asuka Kato; asukakato-tky@umin.ac.jp

\section{ABSTRACT}

Objective: Growing qualitative evidence reveals that many patients with chronic illnesses struggle to rebuild a positive self-image after diagnosis while attempting to find a balance between their current physical status and their ongoing social duties. One factor destabilizing patients' identities is self-stigma, which seems to affect their behavioral goals through decreased self-efficacy. We hypothesized that selfstigma would be an independent factor, distinct from self-efficacy, for developing self-care behaviors in patients with type 2 diabetes.

Methods: We used a consecutive sample of 209 outpatients with type 2 diabetes treated by endocrinologists at two university hospitals, one general hospital and one clinic. We performed multiple linear regression analyses to test the relationship between the patients' activation levels for self-care behaviors (dependent variable) and self-stigma, selfefficacy, and depression symptoms (independent variables), adjusting for covariates involving sociodemographic and clinical characteristics.

Results: In a multiple linear regression mode adjusted for prior covariates, there was significant association between self-stigma and activation levels for self-care behaviors in patients with type 2 diabetes (adjusted $\left.R^{2}=0.26, F(12,196)=7.20, p<0.001\right)$. The standardized partial regression coefficient of self-stigma was $-0.23(p=0.001)$, whereas that of self-efficacy was $0.19(p=0.007)$.

Conclusions: Self-stigma is a negative independent factor, separate from self-efficacy, affecting the self-care behaviors of patients with type 2 diabetes. Self-stigma also has, at least, a similar impact on self-care behaviors to that of self-efficacy. To optimize treatment outcomes, patients' self-stigma should be minimized, whereas their self-efficacy should be enhanced.

\section{INTRODUCTION}

Type 2 diabetes requires considerable selfmanagement in patients' daily lives, to prevent serious morbidity and mortality. ${ }^{1}{ }^{2}$ They are first required to understand the necessity of practicing self-care behaviors and can then acquire the knowledge, skills, and

\section{Key messages}

- This study is the first to confirm self-stigma as a factor independent of self-efficacy and to suggest that self-stigma strongly predicts patients' with type 2 diabetes activation levels for self-care behaviors.

- Our results also suggested that the association between self-stigma and self-care behaviors was not mediated by depression symptoms.

- Overall, merely enhancing self-efficacy is inadequate because these patients require help reducing self-stigma.

confidence necessary to actively participate in their treatment. ${ }^{3-6}$ For those suffering from type 2 diabetes, it is essential to manage self-care behaviors to optimize their treatment outcomes. To date, numerous studies have been conducted to investigate factors associated with self-care behaviors.

Self-efficacy has been proven to play a significant role in improving self-care behaviors, including adherence to appropriate diet, exercise, and medication. ${ }^{7-10}$ Self-efficacy is defined as an individual's belief in their personal ability to succeed in a specific situation, perform a given task, or develop certain behaviors, such as a variety of diabetes selfmanagement behaviors. ${ }^{7}$ In clinical practices, educational interventions have predominantly focused on enhancing self-efficacy. ${ }^{11-14}$ Furthermore, previous studies indicate that depression is associated with poor self-care behaviors in patients with type 2 diabetes. ${ }^{15-}$ 17 In the past decade, screening and early interventions for depression have been increased and enhanced in clinical settings. ${ }^{18}$ However, several studies have suggested that enhanced depression care is not necessarily associated with improved diabetes selfmanagement. ${ }^{19-21}$

Furthermore, growing qualitative evidence reveals that many patients with chronic illnesses struggle to rebuild a positive self-image 
after diagnosis, in the attempt to find a balance between their current physical status and their ongoing social duties. $^{22-25}$ One factor destabilizing patients' identities is self-stigma, which affects their behavioral goals through decreased self-efficacy. ${ }^{26-28}$ Self-stigma refers to the prejudicial attitude wherein individuals develop negative attitudes toward themselves because of their condition. ${ }^{28} 29$ Public stigma, also known as social stigma, and self-stigma, are two distinct constructs. ${ }^{26}{ }^{29}$ Previous studies have indicated that merely perceiving public stigma does not necessarily lead to self-stigma. ${ }^{26}{ }^{29}$ For type 2 diabetes, a qualitative study indicates that self-stigma is associated with a poor attitude toward self-care behaviors, thereby strongly suggesting that it is self-stigma, as opposed to public stigma, that will likely result either in blind acceptance or overt hesitation when receiving medical advice; consequently, self-stigma negatively impacts treatment outcomes in patients with type 2 diabetes. ${ }^{25}$

To the best of our knowledge, studies have yet to explore quantitatively whether self-stigma would hinder patients' with type 2 diabetes activation levels for improving their self-management. Therefore, we conducted a cross-sectional study to examine the relationship between self-stigma and patients' activation levels for their self-care behaviors. We hypothesized that selfstigma would be an independent factor, separate from self-efficacy, for self-care behaviors and that a higher level of self-stigma for the illness would lower a patient's activation level for self-care behaviors.

\section{METHODS}

Study design, setting, and participants

A questionnaire-based, cross-sectional study was conducted between November 2013 and March 2014. Consecutive sampling was used to recruit all outpatients with type 2 diabetes who visited an endocrinologist on a specific date and at four locations in Japan, specifically, two university hospitals, one non-university-affiliated hospital, and one non-university-affiliated clinic. Patients were recruited through their physicians. After obtaining permission from the physicians, the patients received an explanation of the study's purpose by the research staff, after which written informed consents were collected. Inclusion criteria were as follows: presence of type 2 diabetes; aged 20-74 years; ability to read and speak Japanese; no diagnosis of dementia and psychosis; and no urgent medical procedures or examinations needed. Patients completed a questionnaire, taking approximately 15-20 min.

This study was approved in advance by the Research Ethics Committee of the University of Tokyo Graduate School of Medicine and Faculty of Medicine, and by each participating facility.

\section{Variables}

Participants' sociodemographics included sex, age, education (in years), and marital status. A patient's level of education was collected as categorical data (have not graduated high school, have graduated high school, technical/junior college, or earned bachelor's degree or higher) and then converted into years of schooling. Marital status was collected as categorical data (married, unmarried, divorced, or bereaved) and then summarized into two categories (married or unmarried/ divorced/bereaved).

Participants' clinical information, such as body mass index (BMI), time since diagnosis (in months), injection therapy, diabetes-related complications, and hemoglobin A1c level (HbA1c), was also collected. Injection therapy was collected as categorical data (oral hypoglycemic agents, insulin injections, insulin injections and oral hypoglycemic agents, other injectable medications (other than insulin), or lifestyle). This information was then summarized into two categories (injection use or non-use). The number of diabetes-related complications was calculated as the simple sum of six complications, referring to the Diabetes Complications Index (DCI). ${ }^{30}$ The score ranged from 0 to 6 . HbAlc level was completed based on a copy of the laboratory results received that day.

\section{Self-stigma}

The Self-Stigma Scale was used to assess the level of selfstigma. $^{31}$ The reliability and validity of the scale's Japanese version (SSS-J) were reported previously. ${ }^{32}$ The scale comprises 39 assessment items, allowing four responses on a Likert scale: strongly disagree, disagree, agree, and strongly agree, scored $0,1,2$, and 3 , respectively. The total possible scores ranged from 0 to 117 , and the score was treated as continuous. A higher score represents a higher level of self-stigma. In this study, the scale had an internal consistency of 0.96 .

\section{Patient activation}

The Patient Activation Measure (PAM-13) was used to assess patient self-engagement in the treatment. ${ }^{33-35}$ The PAM-13 can be used as a suitable approximation for self-care behaviors since behaviors are clearly associated with patients' activation levels. Patient activation is a concept that includes a comprehensive approach to a number of elements related to activation, including the knowledge, skills, confidence, and behaviors that a patient needs to manage their illness. Therefore, in this study, the PAM-13 was used to assess patients' self-care behaviors.

The PAM-13 is a clinically used, highly reliable and valid scale containing 13 questions, scored using a Likert scale (strongly disagree, disagree, agree, strongly agree, and not applicable). A score of 1, 2, 3, 4, or missing was chosen, with a possible total score of 13 to 52. These scores were then converted into an interval scale (0-100). A high score corresponds with a positive attitude toward the necessary behavioral changes during the course of treatment. The Japanese version of the PAM-13 for mental health was used without including 
the words 'mental health' as stipulated by the scale's developer. In this study, the scale had an internal consistency of 0.85 .

\section{Self-efficacy}

The General Self-efficacy Scale was applied to assess individual strengths in the general self-efficacy across a variety of everyday life settings. ${ }^{36}$ It is reliable, valid, and commonly used to measure self-efficacy in Japan; it is a 16-item scale and uses dichotomous (yes/no) questions. The total possible scores have a range of $0-16$, and the score was treated as continuous. A higher score represents a higher level of self-efficacy. In this study, the scale had an internal consistency of 0.84 .

\section{Depression symptoms}

The nine-item depression module of the Patient Health Questionnaire (PHQ-9) was used to assess patients' depression symptoms over the 2 weeks prior to filling out the questionnaire. ${ }^{37} 38$ The PHQ-9 is a reliable and valid measure of depression severity for clinical use. Each item is scored on the DSM-IV (Diagnostic and Statistical Manual of Mental Disorders-IV) criteria from 0 (not at all) to 3 (nearly every day). The total possible scores have a range of $0-36$, and the score was treated as continuous. In this study, the scale had an internal consistency of 0.86 .

\section{Statistical methods}

Descriptive statistics were calculated using means and SDs, or numbers and percentages, based on the nature of the variables. Dummy variables were created for categorical variables (ie, sex, marital status, and injection therapy). Patient activation was considered a dependent variable, whereas self-stigma, self-efficacy, and depression symptoms were considered independent variables. Each independent variable's relationship to the dependent variable was evaluated using scatterplots and Pearson's correlation coefficient. Before analyses, we tested the model's assumptions: linearity of the relationship among the dependent and independent variables, the homogeneity of variance (relation between the standardized and studentized residuals), the normality of residuals (histogram and normal QQ plot of the residuals), and multicollinearity (variance inflation factor (VIF) and tolerance test).

Multiple linear regression models were analyzed to assess the independent effect of self-stigma on patient activation for self-care behaviors, and two models were constructed. Based on literature reviews, we adjusted for covariates from the possible influence of sociodemographic and clinical variables including sex, age, BMI, diabetes duration, injection therapy, number of diabetesrelated complications, HbAlc, education, and marital status. These sociodemographic and clinical variables, except sex, injection therapy, and marital status, were included in the models as continuous variables. A direct method was used for the multiple linear regression analyses.

To examine the models' predictive capacity, analysis of variance was used to test the significance of the overall regression equation by calculating the $\mathrm{F}$ value. The adjusted coefficients of determination were calculated to evaluate the explanatory capacity of patient activation. Regression coefficients and standardized partial regression coefficients were also calculated to quantify the degree of association between the dependent and independent variables. All analyses were performed using SPSS V.23.0 (SPSS Japan Inc, Tokyo, Japan).

\section{RESULTS}

\section{Participants}

Physicians recruited 259 patients with type 2 diabetes and obtained 218 written informed consent forms-a response rate of $84.2 \%$. Of these patients, $217 \mathrm{com}-$ pleted the questionnaire (one patient declined). In the analysis, we excluded five participants who answered all 39 items of the SSS-J with a 'strongly disagree' response because they responded strongly to stigma, and we did not know whether the scale could measure what it was originally intended to assess. We also excluded three participants who answered all 13 items of the PAM-13 with a 'strongly agree' response, as determined by the scale's developer. Therefore, 209 participants were included in our final analysis. The percentage of missing data was zero for all questionnaire items. We did not find any outlier within our study.

\section{Descriptive data}

The participants' sociodemographic and clinical characteristics are shown in table 1 . Of the participants,

Table 1 Sociodemographic and clinical characteristics of participants $(\mathrm{n}=209)$

\begin{tabular}{lc}
\hline Patient characteristics & N $(\%)$ or mean $( \pm$ SD) \\
\hline Sex & \\
$\quad$ Male & $168(80.4)$ \\
Female & $41(19.6)$ \\
Age (years) & $60.2( \pm 10.1)$ \\
BMI (kg/m ${ }^{2}$ ) & $26.3( \pm 5.0)$ \\
Duration of diabetes (months) & $159.1( \pm 113.8)$ \\
Injection therapy & \\
Yes & $73(34.9)$ \\
No & $136(65.1)$ \\
Number of diabetes-related & $0.57( \pm 0.86)$ \\
complications $(0-6)^{\star}$ & \\
HbA1c $(\%)$ & $7.3( \pm 1.2)$ \\
HbA1c (mmol/mol) & $56( \pm 13.1)$ \\
Education (years) & $13.9( \pm 2.3)$ \\
Marital status & \\
$\quad$ Married & $151(72.2)$ \\
Unmarried/divorced/bereaved & $58(27.8)$ \\
\hline
\end{tabular}

*Diabetes Complications Index (DCl).

$\mathrm{BMI}$, body mass index; HbA1c, glycated hemoglobin. 
168 were male $(80.4 \%)$ and 41 were female $(19.6 \%)$; the mean age was $60.2 \pm 10.1$ years. The mean duration of type 2 diabetes was $159.1 \pm 113.8$ months, mean BMI was $26.3 \pm 5.0$, and mean HbAlc was $7.3 \pm 1.2 \%$ (56 $\pm 13.1 \mathrm{mmol} / \mathrm{mol}$ ). The mean number of diabetes-related complications was $0.57 \pm 0.86$, and $34.9 \%$ of participants received injection therapy (insulin or other injectable medications). The mean number for years of education was $13.9 \pm 2.3$, and the majority of patients were married $(72.2 \%)$.

Table 2 shows descriptive analysis of self-stigma and patient activation (PAM-13) levels in participants with HbA1c and diabetes-related complications. Participants were grouped into two categories based on the median HbAlc: lower than $7 \%(53 \mathrm{mmol} / \mathrm{mol})$ and higher than or equal to $7 \%(53 \mathrm{mmol} / \mathrm{mol})$. The means of selfstigma and patient activation scores in the lower group were $68.7 \pm 17.6$ and $53.5 \pm 9.2$, respectively, and in the higher group, they were $73.4 \pm 15.3$ and $50.2 \pm 9.2$, respectively. We found the difference in the two groups' mean scores of self-stigma to be statistically significant (t (207) $=2.04, p=0.043$ ). We also found the difference in the two groups' mean scores of patient activation to be statistically significant $(\mathrm{t}(207)=2.62, \mathrm{p}=0.009)$.

Participants were also grouped into three categories based on the number of diabetes-related complications: 0,1 , and 2 or more complications. The means of selfstigma and patient activation scores in the 0 complication group were $69.1 \pm 16.8$ and $52.5 \pm 9.6$, respectively; in the one complication group, they were $73.4 \pm 15.8$ and $50.8 \pm 8.3$, respectively, and in the two or more

Table 2 Self-stigma and patient activation (PAM-13) levels in participants with $\mathrm{HbA1c}$ and diabetes-related complications $(n=209)$

\begin{tabular}{|c|c|c|}
\hline Patient characteristics & $\begin{array}{l}\text { Self-stigma* } \\
\text { Mean (土SD) }\end{array}$ & $\begin{array}{l}\text { Patient } \\
\text { activation† } \\
\text { (PAM-13) } \\
\text { Mean ( } \pm \text { SD) }\end{array}$ \\
\hline \multicolumn{3}{|l|}{$\mathrm{HbA1c}$} \\
\hline $\begin{array}{l}<7 \%(53 \mathrm{mmol} / \mathrm{mol}) \\
(\mathrm{n}=103)\end{array}$ & $68.7( \pm 17.6)$ & $53.5( \pm 9.2)$ \\
\hline $\begin{array}{l}\geq 7 \%(53 \mathrm{mmol} / \mathrm{mol}) \\
(\mathrm{n}=106)\end{array}$ & $73.4( \pm 15.3)$ & $50.2( \pm 9.2)$ \\
\hline \multicolumn{3}{|c|}{ Number of diabetes-related complications $\ddagger$} \\
\hline $0(n=129)$ & $69.1( \pm 16.8)$ & $52.5( \pm 9.6)$ \\
\hline $1(n=52)$ & $73.4( \pm 15.8)$ & $50.8( \pm 8.3)$ \\
\hline$\geq 2(n=28)$ & $76.0( \pm 15.9)$ & $50.8( \pm 9.9)$ \\
\hline \multicolumn{3}{|c|}{ Quality of diabetes-related complications§ } \\
\hline $\begin{array}{l}\text { Without eye problems } \\
(n=161)\end{array}$ & $69.5( \pm 16.6)$ & $52.0( \pm 9.1)$ \\
\hline With eye problems $(n=48)$ & $76.4( \pm 15.8)$ & $51.2( \pm 10.0)$ \\
\hline \multicolumn{3}{|c|}{$\begin{array}{l}\text { *Self-Stigma Scale (SSS-J). } \\
\text { †Patient Activation Measure (PAM-13). } \\
\text { łDiabetes Complications Index (DCI). } \\
\text { §Diabetes-related complications on whether participants had } \\
\text { retinopathy and/or cataract. } \\
\text { HbA1c, glycated hemoglobin. }\end{array}$} \\
\hline
\end{tabular}

complications group, they were $76.0 \pm 15.9$ and $50.8 \pm 9.9$, respectively. In regard to the quality of diabetes-related complications, participants were grouped into two categories: without and with eye problems (retinopathy and/or cataract). The means of self-stigma and patient activation scores in the group without eye problems were $69.5 \pm 16.6$ and $52.0 \pm 9.1$, respectively, and in the group with eye problems, they were $76.4 \pm 15.8$ and $51.2 \pm 10.0$, respectively.

Online supplementary appendix 1 shows Pearson's correlation coefficients between each of the independent and dependent variables (patient activation). All the correlation coefficients were found to be either moderate or weak, and VIFs for each variable were lower than 1.7; therefore, no multicollinearity problems existed.

\section{Main results}

Using multiple linear regression models, associations between self-stigma and patient activation were systematically examined. We adjusted for covariates, including sex, age, BMI, diabetes duration, injection therapy, diabetes-related complications, HbAlc, education, and marital status, in each model. Table 3 shows the results of the multiple linear regression analysis of patient activation as a dependent variable. In model 1 , the adjusted coefficient of determination was $0.23(\mathrm{~F}(11,197)=6.52$, $\mathrm{p}<0.001)$. Self-efficacy was significantly positively associated with patient activation $(0.25, \mathrm{p}<0.001$ (standardized partial regression coefficient)), whereas depression symptoms were significant and negatively associated with patient activation $(-0.16, \mathrm{p}=0.027$ (standardized partial regression coefficient)). When selfstigma was added to the model (model 2), the adjusted coefficient of determination was increased to 0.26 (F $(12,196)=7.20, \mathrm{p}<0.001)$, and self-stigma was found to be significant and negatively associated with patient activation. However, in model 2, depression symptoms were no longer statistically significant $(-0.11, \mathrm{p}=0.131$ (standardized partial regression coefficient)). On the other hand, self-efficacy was still statistically significant; however, the standardized partial regression coefficient of self-efficacy decreased to $0.19(\mathrm{p}=0.007)$, whereas that of self-stigma was $-0.23(\mathrm{p}=0.001)$.

\section{DISCUSSION}

This study was performed to examine the association between self-stigma and self-care behaviors in patients with type 2 diabetes. Self-stigma was found to be both significant and negatively associated with patients' activation levels for their self-care behaviors. In addition, selfefficacy was also found to be a salient predictor of patients' activation levels for their self-care behaviors. When self-stigma was included in the multiple linear regression model, the association between self-efficacy and self-care behaviors was slightly attenuated. However, in our findings, self-stigma had, at least, a similar impact to that of self-efficacy on patients' self-care behaviors. 


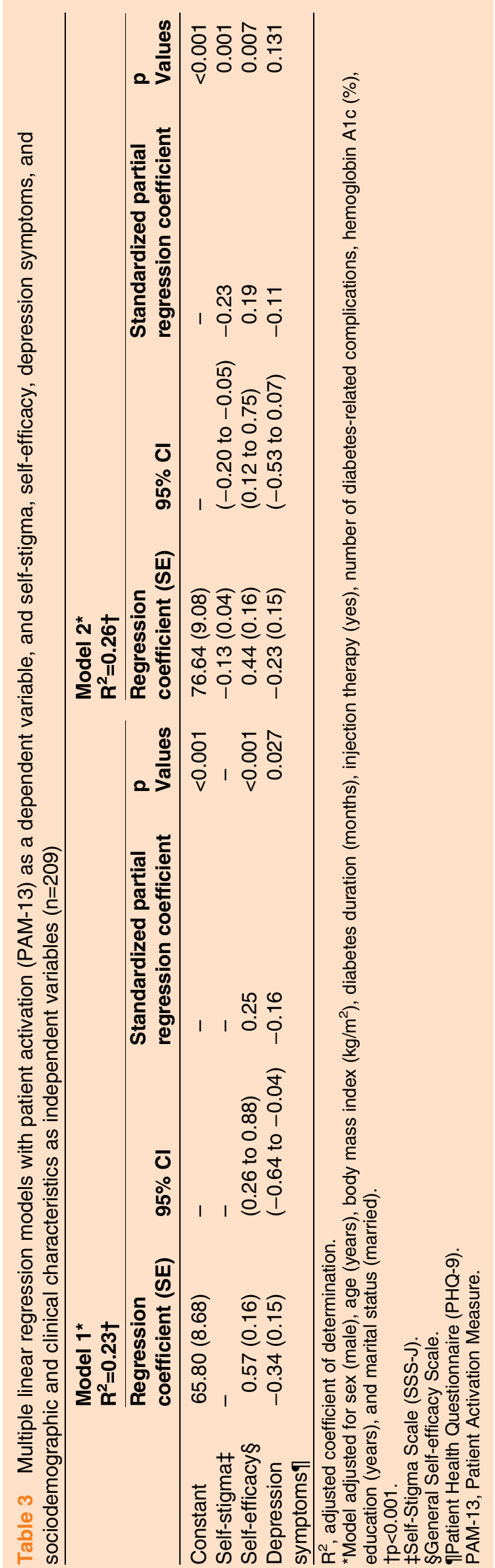

Thus, results suggested that self-stigma strongly predicted patients' with type 2 diabetes activation levels for self-care behaviors.

Furthermore, the correlation between self-stigma and self-care behaviors remained after adjusting for covariates and depression symptoms, demonstrating selfstigma's independent association with self-care behaviors, separate from that of depression symptoms. In previous studies, depression symptoms explained patients' with type 2 diabetes poor attitudes toward self-care behaviors. ${ }^{19-21}$ However, our findings suggested that the association between self-stigma and self-care behaviors was not mediated by depression symptoms. This result is consistent with our previous qualitative study. ${ }^{25}$

This study has several limitations. First, because this was a cross-sectional study, follow-up studies with larger sample sizes will be needed to confirm self-stigma's effects on patients' with type 2 diabetes attitudes toward self-management. Second, all patients participating in this study were recruited from specialist hospitals or clinics. No patients seen regularly by primary care doctors were included and neither were those who had discontinued treatment. Further research will be needed-studying a more representative portion of the population-not only in specialty fields but also in primary care settings. And third, there was a sex and age imbalance in our sample, with the percentage of men at $80.4 \%$ and higher mean age of 60.2 years. In our analysis, sex and age were adjusted as covariates in the multiple linear regression models. We also did not find any significant interaction effects between selfstigma and patient activation with respect to sex $(\beta=0.10 ; p=0.746)$ and age $(\beta=0.34 ; p=0.318)$. Therefore, it is quite unlikely that the sex and age imbalance in this sample impacted our overall findings. Based on our collected data and analysis, a younger sample with a better mix of men and women most likely would not change the overall results.

This study's findings have several implications. First, patients with type 2 diabetes with higher levels of HbA1c who have two or more and/or noticeable complications, such as eye problems, are more likely to suffer from increased self-stigma. Further research with a larger representative sample will be needed to examine how the different types of complications particularly impact selfstigma, which might then affect the activation of selfcare behaviors in patients with type 2 diabetes. Nevertheless, self-stigma can still be experienced by all patients, regardless of age, BMI, diabetes duration, and education. Therefore, the degree of self-stigma should be regularly monitored for all patients, using the selfadministered Self-Stigma Scale. ${ }^{31}{ }^{32}$ Second, separate from self-efficacy, self-stigma is independently associated with self-care behaviors in patients with type 2 diabetes. Simply enhancing self-efficacy is insufficient. Rather, patients need help reducing any self-stigma by developing a positive attitude toward type 2 diabetes to support their self-management throughout the course of their 
illness and to optimize their treatment outcomes. Further studies will be needed to discover which method of intervention would be most effective for reducing self-stigma. In psychiatric patients, there is evidence that self-stigma reduction programs are effective in enhancing coping skills for self-stigma, promoting their readiness to change their problematic behavior, and facilitating their treatment adherence. ${ }^{39}{ }^{40}$ Similar effects may be expected in patients with type 2 diabetes, with improved treatment adherence by lowering the levels of self-stigma through patient education programs.

\section{Author affiliations}

${ }^{1}$ Division of Social Medicine, Graduate School of Medicine, The University of Tokyo, Tokyo, Japan

${ }^{2}$ The Health Care Science Institute, Tokyo, Japan

${ }^{3}$ Department of Internal Medicine, School of Medicine, Teikyo University,

Tokyo, Japan

${ }^{4}$ Mitsui Memorial Hospital, Tokyo, Japan

${ }^{5}$ The Institute for Adult Diseases Asahi Life Foundation, Tokyo, Japan

${ }^{6}$ Department of Diabetes and Metabolic Diseases, Graduate School of

Medicine, The University of Tokyo, Tokyo, Japan

${ }^{7}$ Department of Health and Social Behavior, School of Public Health, The University of Tokyo, Tokyo, Japan

Acknowledgements The authors would like to acknowledge all the endocrinologists for their cooperation in recruiting the patients for this study. They are also grateful to the many graduate students who helped to collect the data. Similarly, the authors would like to express their appreciation to all of the study participants.

Contributors AK conceptualized and designed the study. AK coordinated the study; acquired, analyzed, and interpreted the data, and prepared the paper. $\mathrm{HH}$ helped to analyze and interpret the data. AK and $\mathrm{HH}$ held primary responsibility for data access. YF, SF, AI, YO, RS, TY, KU, and TK made significant contributions to the critical interpretation of the results in terms of important practical content. All the authors read and approved of the final version for the manuscript.

Competing interests None declared.

Patient consent Obtained.

Ethics approval This study was approved in advance by the Research Ethics Committee of the University of Tokyo Graduate School of Medicine and Faculty of Medicine, and by each participating facility.

Provenance and peer review Not commissioned; externally peer reviewed.

Data sharing statement No additional data are available.

Open Access This is an Open Access article distributed in accordance with the Creative Commons Attribution Non Commercial (CC BY-NC 4.0) license, which permits others to distribute, remix, adapt, build upon this work noncommercially, and license their derivative works on different terms, provided the original work is properly cited and the use is non-commercial. See: http:// creativecommons.org/licenses/by-nc/4.0/

\section{REFERENCES}

1. UK Prospective Diabetes Study (UKPDS) Group. Intensive blood-glucose control with sulphonylureas or insulin compared with conventional treatment and risk of complications in patients with type 2 diabetes (UKPDS 33). UK Prospective Diabetes Study (UKPDS) Group. Lancet 1998;352:837-53.

2. The Diabetes Control and Complications Trial Research Group. The effect of intensive treatment of diabetes on the development and progression of long-term complications in insulin-dependent diabetes mellitus. The Diabetes Control and Complications Trial Research Group. N Engl J Med 1993;329:977-86.
3. Bodenheimer $\mathrm{T}$, Lorig $\mathrm{K}$, Holman $\mathrm{H}$, et al. Patient self-management of chronic disease in primary care. JAMA 2002;288:2469-75.

4. Lorig KR, Sobel DS, Stewart AL, et al. Evidence suggesting that a chronic disease self-management program can improve health status while reducing hospitalization: a randomized trial. Med Care 1999;37:5-14.

5. Von Korff M, Gruman J, Schaefer J, et al. Collaborative management of chronic illness. Ann Intern Med 1997;127:1097-102.

6. Hibbard JH, Mahoney ER, Stock R, et al. Do increases in patient activation result in improved self-management behaviors? Health Serv Res 2007;42:1443-63.

7. Bandura A. Self-efficacy: toward a unifying theory of behavioral change. Psychol Rev 1977;84:191-215.

8. Nakahara R, Yoshiuchi $\mathrm{K}$, Kumano $\mathrm{H}$, et al. Prospective study on influence of psychosocial factors on glycemic control in Japanese patients with type 2 diabetes. Psychosomatics 2006;47:240-6.

9. Al-Khawaldeh OA, Al-Hassan MA, Froelicher ES. Self-efficacy, self-management, and glycemic control in adults with type 2 diabetes mellitus. J Diabetes Complicat 2012;26:10-16.

10. Sousa VD, Zauszniewski JA, Musil CM, et al. Relationships among self-care agency, self-efficacy, self-care, and glycemic control. Res Theory Nurs Pract 2005;19:217-30.

11. Glasgow RE, Toobert DJ, Hampson SE, et al. Improving self-care among older patients with type II diabetes: the "Sixty Something..." Study. Patient Educ Couns 1992;19:61-74.

12. Reichard $\mathrm{P}$, Toomingas $\mathrm{B}$, Rosenqvist $\mathrm{U}$. Changes in conceptions and attitudes during five years of intensified conventional insulin treatment in the Stockholm Diabetes Intervention Study (SDIS). Diabetes Educ 1994;20:503-8.

13. Anderson RM, Funnell MM, Butler PM, et al. Patient empowerment. Results of a randomized controlled trial. Diabetes Care 1995;18:943-9.

14. Trief PM, Teresi JA, Eimicke JP, et al. Improvement in diabetes self-efficacy and glycaemic control using telemedicine in a sample of older, ethnically diverse individuals who have diabetes: the IDEATel project. Age Ageing 2009;38:219-25.

15. Lustman PJ, Anderson RJ, Freedland KE, et al. Depression and poor glycemic control: a meta-analytic review of the literature. Diabetes Care 2000;23:934-42.

16. Gross R, Olfson M, Gameroff MJ, et al. Depression and glycemic control in Hispanic primary care patients with diabetes. $J$ Gen Intern Med 2005:20:460-6.

17. Ciechanowski PS, Katon WJ, Russo JE. Depression and diabetes: impact of depressive symptoms on adherence, function, and costs. Arch Intern Med 2000;160:3278-85.

18. Evans DL, Charney DS, Lewis L, et al. Mood disorders in the medically ill: scientific review and recommendations. Biol Psychiatry 2005:58:175-89.

19. Petrak F, Herpertz S. Treatment of depression in diabetes: an update. Curr Opin Psychiatry 2009;22:211-17.

20. Williams JW Jr, Katon W, Lin EH, et al. The effectiveness of depression care management on diabetes-related outcomes in older patients. Ann Intern Med 2004;140:1015-24.

21. Paile-Hyvärinen M, Wahlbeck K, Eriksson JG. Quality of life and metabolic status in mildly depressed women with type 2 diabetes treated with paroxetine: a single-blind randomised placebo controlled trial. BMC Fam Pract 2003;4:7.

22. Charmaz K. Loss of self: a fundamental form of suffering in the chronically ill. Social Health IIIn 1983;5:168-95.

23. Herzlich C. Health and illness: a social psychological analysis. Oxford, England: Academic Press, 1973.

24. Radley A. Making sense of illness. Thousand Oaks, CA: Sage, 1994.

25. Kato A, Fujimaki Y, Fujimori S, et al. Impact of self-stigma on self-care management behaviors in patients with type 2 diabetes: a mixed methods study [abstract]. Diabetes 2015;64(Suppl 1):A234.

26. Corrigan PW, Watson AC. The paradox of self-stigma and mental illness. Clin Psychol-Sci Pr 2002;9:35-53.

27. Link BG, Struening EL, Neese-Todd S, et al. Stigma as a barrier to recovery: the consequence of stigma for the self-esteem of people with mental illness. Psychiatr Serv 2001;52:1621-6.

28. Corrigan PW, Watson AC, Barr L. The self-stigma of mental illness: implications for self-esteem and self-efficacy. J Soc Clin Psychol 2006;25:875-84.

29. Rüsch N, Angermeyer MC, Corrigan PW. Mental illness stigma: concepts, consequences, and initiative to reduce stigma. Eur Psychiat 2005;20:529-39.

30. Fincke BG, Clark JA, Linzer M, et al. Assessment of long-term complications due to type 2 diabetes using patient self-report: the diabetes complications index. J Ambul Care Manage 2005;28:262-73. 
31. Mak WW, Cheung RY. Self-stigma among concealable minorities in Hong Kong: conceptualization and unified measurement. Am J Orthopsychiatry 2010;80:267-81.

32. Kato A, Takada M, Hashimoto $\mathrm{H}$. Reliability and validity of the Japanese version of the self-stigma scale in patients with type 2 diabetes. Health Qual Life Outcomes 2014;12:179.

33. Fujita E, Kuno E, Kato D, et al. Development and validation of the Japanese version of the patient activation measure 13 for mental health. Seishin Igaku (Clinical Psychiatry) 2010;52: 765-72.

34. Hibbard JH, Mahoney E, Stockard J, et al. Development and testing of a short form of the patient activation measure. Health Serv Res 2005;40:1918-30.

35. Hibbard JH, Stockard J, Mahoney ER, et al. Development of the Patient Activation Measure (PAM): conceptualizing and measuring activation in patient and consumers. Health Serv Res 2004;39:1005-26.
36. Sakano Y, Tohjoh M. The General Self-Efficacy Scale (GSES): scale development and validation. Jpn J Behav Ther 1986;12:73-82.

37. Muramatsu K, Miyaoka H, Kamijima K, et al. The patient health questionnaire, Japanese version: validity according to the mini-international neuropsychiatric interview-plus. Psychol Rep 2007; 101:952-60. (PHQ-9 Copyright ( 1999 Pfizer Inc. all rights reserved)

38. Spitzer RL, Williams JB, Kroenke K, et al. Validation and utility of a self-report version of PRIME-MD: the PHQ primary care study. Primary Care Evaluation of Mental Disorders. Patient Health Questionnaire. JAMA 1999;282:1737-44.

39. Luoma JB, Kohlenberg BS, Hayes SC, et al. Reducing self-stigma in substance abuse through acceptance and commitment therapy: model, manual development, and pilot outcomes. Addict Res Theory 2008;16:149-65.

40. Maclnnes DL, Lewis M. The evaluation of a short group programme to reduce self-stigma in people with serious and enduring metal health problems. J Psychiatr Mental Health Nurs 2008;15:59-65. 